\title{
EVENTUAIS REFLEXOS JURÍDICOS INCIDENTES DO NAMORO QUALIFICADO SOBRE O BENEFÍCIO PREVIDENCIÁRIO PENSÃO POR MORTE
}

Arthur Leonardo Silva Morais

Universidade do Oeste Paulista - UNOESTE, Curso de Direito, PRESIDENTE Prudente, SP. E-mail: arthurleonardo1@hotmail.com

\section{RESUMO}

O presente trabalho buscou de forma clara e sucinta analisar uma recente espécie de relacionamento afetivo, que ficou conhecido pelo termo namoro qualificado, avaliando se os namorados neste caso podem ser considerados dependentes previdenciários, e, portanto, titulares do benefício previdenciário pensão por morte. A metodologia utilizada foi a pesquisa em bibliografias, doutrinas, jurisprudências e analise do texto de lei. O que permitiu concluir que a espécie de namoro não faz incidir efeitos jurídicos dentro os participantes, não vinculando patrimonialmente as partes, afastando-se assim, a possibilidade de um ou outro, ser titular do benefício previdenciário.

Palavras-chave: Namoro qualificado. Pensão por morte. União-estável. Benefício previdenciário. Intuitu familiae.

\section{EVIDENT LEGAL REFLECTIONS INCIDENTS OF THE QUALIFIED DATING ON THE BENEFIT OF DEATH PENSION}

\begin{abstract}
The present work sought in a clear and succinct way to analyze a recent kind of affective relationship, which was known by the term qualified dating, evaluating if the boyfriends in this case can be considered social security dependents, and, therefore, pension benefit pension by death. The methodology used was the research in bibliographies, doctrines, jurisprudence and analysis of the text of law. This made it possible to conclude that the kind of courtship does not have legal effects on the participants, and does not bind the parties in equity, thus excluding the possibility of one or the other being entitled to the social security benefit.
\end{abstract}

Keywords: Qualified dating. Pension for death. Stable union. Social security benefit. Intuitu familiase. 


\section{INTRODUÇÃO}

É certo que a sociedade vem se modernizando em diversos setores, inclusive no âmbito familiar. Antes da Carta Magna de 1988 o único modelo familiar que detinha de proteção estatal era o matrimônio institucionalizado, o que sofreu latente mudança.

Hoje já se reconhece outras estruturas familiares como a união estável, inclusive, gerando reflexos jurídicos dentre os companheiros. Podemos citar como exemplo, o reconhecimento pelo judiciário, do instituto do namoro qualificado, que teve visibilidade na histórica decisão do STJ (3a Turma, REsp.no 1.454,643-RJ, DJe. 10.03.2015), que teve como relator o ministro Marco Aurélio Bellizze.

Dessa forma, por se tratar da uma recente espécie de relacionamento, levanta-se a questão: há possibilidade dos indivíduos na constância do namoro qualificado vierem a ser titulares de pensão por morte? Se presume dependência financeira dos mesmos?

Assim sendo, com tais propósitos se moldam o presente trabalho, tendo como escopo principal a análise dos supostos reflexos jurídicos e que forma, o namoro qualificado atuaria sobre o benefício previdenciário - pensão por morte?

\section{METODOLOGIA}

A metodologia empregada foi a dedutiva, dessa forma foi feito a analise em livros, doutrinas, artigos científicos, matéria jornalística, jurisprudência e texto de lei.

\section{DISCUSSÃO}

\section{NAMORO QUALIFICADO E PENSÃO POR MORTE}

De início é necessário fazer a distinção entre união estável e namoro qualificado tendo em vista a grande semelhança entre ambos.

Assim, a união estável consiste na união de duas pessoas movida pelo amor, carinho, respeito e companheirismo, é a junção de duas vidas, com o respeitável propósito de constituir família, de viver uma vida juntos.

Tal núcleo familiar ganhou proteção estatal com a promulgação da constituição cidadã em 1988, aduzindo o art. 226 §3으 (BRASIL, 1988, online) que “[...] é reconhecida a união estável entre o homem e a mulher como entidade familiar, devendo a lei facilitar sua conversão em casamento."

Neste embalo o Código Civil trouxe um capitulo reservado somente para o referido tema, elencado entre os arts. 1.723 à 1.727. A respeito, traz à baila o artigo 1.723 (BRASIL, 2002, online), inspirado na Lei n.․ 9.278/66, que:

Art. 1.723. É reconhecida como entidade familiar a união estável entre o homem e a mulher, configurada na convivência pública, contínua e duradoura e estabelecida com o objetivo de constituição de família.

Dessa forma, pelo o que conceitua a lei, a união estável se caracteriza com o conhecimento público e notório, combinado com uma relação continua, onde não há periódicas separações, assim como, seja exercida de forma duradoura, isto é, que se estenda no tempo, e que fique caracterizado o "intuitu familiae", ou seja, intuito de constituir família, o objetivo de formar prole é o marco principal para a configuração dessa espécie de núcleo familiar.

Nessa esteira, entende os Egrégios Tribunais espalhados pelos estes federativos:

TJ-MG - Apelação Cível AC 10024110578655001 MG (TJ-MG)

Jurisprudência $\cdot$ Data de publicação: 12/09/2013

Ementa: DIREITO DE FAMÍLIA - APELAÇÃO - AÇÃO DE RECONHECIMENTO DE UNIÃO ESTÁVEL - CONVIVÊNCIA PÚBLICA, CONTÍNUA E DURADOURA - OBJETIVO DE CONSTITUIR FAMÍLIA - AUSÊNCIA DE PROVA - RECURSO DESPROVIDO. - Não há como reconhecer a existência de união estável, ante a ausência de prova de que o casal tenha mantido convivência pública, contínua e duradoura, com o objetivo de constituir família, e não 
simples namoro ou relacionamento passageiro e esporádico. (TJ-MG, 2013, on-line) (Grifo nosso)

\begin{abstract}
TJ-SE - APELAÇAO CÍVEL AC 2010215409 SE (TJ-SE)
Jurisprudência $\bullet$ Data de publicação: 17/12/2010

Ementa: PROCESSO CIVIL - APELAÇAO CÍVEL - AÇAO DE RECONHECIMENTO DE UNIÃO ESTÁVEL C/C DISSOLUÇAO - PRESENÇA DOS REQUISITOS PARA A COMPROVAÇAO DA UNIÃO ESTÁVEL - PLEITO PROCEDENTE - FIM DA UNIÃO ESTÁVEL ANTES DO FALECIMENTO DO COMPANHEIRO - ALEGAÇAO INFUNDADO DOS APELANTES - CONHECIMENTO E IMPROVIMENTO DO RECURSO. - É reconhecida como entidade familiar a união estável entre homem e mulher, configurada na convivência pública, contínua e duradoura e estabelecida com objetivo de constituição de família . - Desvencilhando-se a parte autora de comprovar os elementos indispensáveis à constituição da união estável, quais sejam, a convivência pública e, principalmente, o intuito de constituir família, a improcedência do apelo é medida que se impõe. (TJ-SE, 2010, on-line) (Grifo nosso)
\end{abstract}

Dessa forma, o namoro qualificado muito se assemelha com o instituto da união estável, pois nota-se presente quase todos os requisitos, o que na prática, se torna difícil uma análise certeira se determinado relacionamento está ou não abarcado pela espécie de namoro.

Assim, a diferença se encontra no fato de que no namoro qualificado os enamorados projetam para o futuro o objetivo de constituir família, diferentemente da união estável, onde o intuito de constituir família é presente, tanto assim, que se equipara ao casamento, no namoro qualificado os participantes apenas querem "curtir" a agradável companhia de seu parceiro ou se conhecerem melhor, sem as responsabilidades de uma união estável.

Ressalta-se, que no namoro qualificado a relação é de conhecimento comum, concretizado pela continuidade e estabilidade, porém os enamorados ainda não querem embarcar na difícil missão de constituir familia.

O termo namoro qualificado tomou projeção após o julgamento do Recurso Especial (№ 1.454.643) remetido a Terceira Turma do STJ, que teve como Relator o Ministro Marco Aurélio Bellizze.

Na ação, a demandante visava o reconhecimento da união estável no período em que os até então namorados viveram juntos fora do país, o caso se iniciou quando o requerido aceitou uma proposta de emprego e se mudou pra Polônia, mais tarde, após o termino do curso superior a requerente se mudou para o mesmo pais, a fim de aprimorar seus conhecimentos em língua inglesa.

Ocorre que viveram nessa situação por dois anos, quando o requerido com a intenção de contrair matrimonio com a requerente formalizou o pedido de casamento, passando assim a ser noivos. Em virtude de tal fato, o mesmo, com recursos próprios adquiriu um imóvel no Brasil para futura moradia do casal.

Destarte, que após o termino do casamento, a ex-esposa roga no judiciário o reconhecimento da união estável na época em que conviveram juntos fora do país, a fim de que o imóvel adquirido antes do casamento seja dividido em parte iguais entre ela e o ex-cônjuge.

$\mathrm{Na}$ decisão, o relator deu provimento ao recurso apresentado pelo ex-esposo, não reconhecendo a união estável e por lógica a dissolução da mesma, o julgador entendeu que não houve a prevalência dos requisitos caracterizadores da união estável - relacionamento público, continuo, estável com intuito de constituir família - tendo em vista, que o arcabouço probatório deixou claro que os então namorados adiaram para o futuro o objetivo de formar núcleo familiar.

Com maestria, o Relator aponta:

Nesse contexto, é de se reconhecer a configuração, na verdade, de um namoro qualificado, que tem, no mais das vezes, como único traço distintivo da união estável, a ausência da intenção presente de constituir uma família. Quando muito há, nessa espécie de relacionamento amoroso, o planejamento, a projeção de, no futuro, constituir um núcleo familiar. (STJ, 2015, on-line) (Grifo do autor) 
Em outro ponto, superado tais fatos, é necessário discorrer sobre o benefício previdenciário pensão por morte, que tem correspondência legal no art. 201, incisos I e V da Constituição Federal e nos arts. 74 e sequentes da Lei n.o 8.13/91.

O benefício é destinado aos dependentes do segurado da previdência social, previsto no art. 16 da Lei 8.213/91, e tem como escopo substituir a remuneração daquele que veio a óbito, no intuito de não deixar desamparada a família de segurado em momento de excepcional fatalidade.

A proposito sobre tal tema, preleciona os juristas Castro e Lazzari (2018, p. 885):

A pensão por morte é o benefício previdenciário pago aos dependentes do segurado, homem ou mulher, que falecer, aposentado ou não, conforme previsão expressa do art. 201, V, da Constituição Federal. Trata-se de prestação de pagamento continuado, substitutiva de remuneração do segurado falecido.

O art. 16 da Lei 8.213/91 faz menção àqueles que tem direito ao benefício como dependentes, e expressamente enumera três classes, onde a existência de uma das classes de dependentes faz afastar o direito a pensão das classes sucedentes.

- 1a Classe: Cônjuge, companheiro (a), filhos não emancipados (salvo se decorrente de colação de grau) menores de 21 anos, filhos inválidos de qualquer idade e equiparados a filhos (enteados e menor tutelado);

- 2a Classe: Pais;

- 3a Classe: Irmão menor de 21 anos e irmão inválido de qualquer idade.

Vale expor, que a dependência econômica da primeira classe é presumida, de modo que estes não precisam comprovar que necessitavam diretamente dos proventos do "de cujos" para patrocinar sua subsistência, o que não acontece com as demais classe, as quais necessita haver a comprovação de dependência econômica para fundamentar a concessão do benefício previdenciário.

\section{REFLEXOS JURIDICOS INCIDENTES DO NAMORO QUALIFICADO SOBRE A PENSÃO POR MORTE}

Por todo o exposto, nota-se que a questão principal ronda na indagação outra hora feita no início do estudo, a convivência publica, continua e duradoura sem intuito de constituir família faz nascer o direito do namorado (a) (na constância do namoro qualificado) ser beneficiário do benefício previdenciário pensão por morte?

A resposta que se tem é negativa, chegando-se a conclusão que o namoro qualificado não gera efeitos jurídicos entres os participantes, tendo em vista a falta de "affectio maritalis".

De forma preliminar observa-se que o namoro qualificado, mesmo tendo uma maior atenção nos últimos anos, haja vista a grande semelhança com a união estável, ainda é uma espécie de namoro, e como tal, não faz jus a proteção estatal, mesmo porque se trata de algo corriqueiro na vida das pessoas, onde as mesmas buscam se utilizar de tais experiências para concretizar algo futuro ou até mesmo por se sentirem cômodos vivendo sem a seriedade que uma união estável ou um casamento proporciona.

Nota-se que a referida espécie de relacionamento não é considerado uma entidade familiar, tendo em vista a falta do "affectio maritalis", primordial a configuração da união estável, outrossim, observa-se que somente os institutos da união estável e do casamento detém de proteção legal, sendo impossível assim, a espécie de namoro gerar efeitos jurídicos entres os participantes.

Dessa forma, o termino entre os namorados geraria efeitos somente de ordem pessoal, pois, observa-se, que mesmo na vivencia da espécie de namoro, as partes vivem uma vida livre, e com objetivos autônomos, não existindo a obrigação de assistência, auxílio financeiro, etc.

Vale expor, que o fato do namoro qualificado não incidir efeitos jurídicos não afasta a possibilidade das partes, rogar no judiciário eventuais prejuízos de ordem moral e material, até 
mesmo meação de imóvel adquirido na constância do referido namoro, se ambos os enamorados ajudaram a conquistar.

Em outra perspectiva, observa-se também que o escopo primordial do benefício pensão por morte é não deixar desamparados os dependentes do falecido, e partindo da premissa, de que a convivência entre os namorados não faz presumir a dependência financeira (pois ambos ainda vivem uma vida onde buscam até então, objetivos distintos), os participantes em virtude de tal afirmativa, não completa os requisitos necessários a concessão da pensão

A proposito disso, afirmando tal ponto, constata-se que o rol de dependentes apenhados na lei previdenciária somente faz menção aos que viveram sobre o instituto do matrimonio e da união estável, dessa forma, por ser o rol taxativo, não cabe outra interpretação a não ser esta, afastando assim, a recente espécie de namoro.

Nesse sentido preleciona os juristas MALUF e MALUF (2013, p. 372):

No namoro qualificado, por outro lado, embora possa existir um objetivo futuro de constituir família, não há ainda essa comunhão de vida. Apesar de se estabelecer uma convivência amorosa pública, contínua e duradoura, um dos namorados, ou os dois, ainda preserva sua vida pessoal e sua liberdade. Os seus interesses particulares não se confundem no presente, e a assistência moral e material reciproca não é totalmente irrestrita.

Nesse passo, a conclusão que se chega é que não há efeitos jurídicos decorrente do namoro qualificado, pois os participantes não vivem sobre a posse de casados, não obtendo assim, vinculo jurídico, tendo em vista a falta do intuito de constituir família.

\section{CONSIDERAÇÕES FINAIS}

Nessa toada, cumpre dizer que os participantes do namoro, ainda que qualificado, não fazem jus ao benefício previdenciário pensão por morte, tendo em vista que não contemplam os requisitos expostos na lei previdenciária, quais sejam: qualidade de segurado do "de cujus" e qualidade de dependente do beneficiário.

Assim nota-se que por mais que exista a qualidade de segurado do falecido, faltaria qualidade de dependente pois, como explicitado, a legislação previdenciária se dispôs a proteger apenas os institutos da união estável e do casamento.

Dessa forma, pela falta de "intuitu familiae", o namoro qualificado, embora pertencente dos requisitos objetivos da união estável (relacionamento público, estável e duradouro), fica aquém de completar o requisito subjetivo (intuito de constituir família), não sendo possível assim, um dos namorados ser dependente do outro, no que se refere a concessão do benefício previdenciário.

\section{REFERÊNCIAS BIBLIOGRÁFICAS}

BRASIL, Constituição (1988). Constituição: República Federativa do Brasil. Brasília, DF: Senado Federal, 1988. Disponível em: < http://www2.camara.leg.br/atividadelegislativa/legislacao/Constituicoes_Brasileiras/constituicao1988.html/Constituiode1988.pdf >. Acessado em 30 de jul. 2018.

BRASIL, Código Civil. Lei no 10.406 de 10 de Janeiro de 2002. Disponível em: < http://www.planalto.gov.br/ccivil_03/Leis/2002/I10406.htm >. Acessado em 30 de jul. 2018.

CASTRO, Carlos Alberto Pereira de; LAZZARI, João Batista, Manual de Direito Previdenciário. Rio de Janeiro: Editora Forense, 2018, Edição 21. 
MALUF, Carlos Alberto Dabus; MALUF, Adriana Caldas do Rego Freitas Dabus. Curso de Direito de Família. Editora Saraiva, 2013, p. 372.

STJ. RECURSO ESPECIAL: REsp 1454643 RJ 2014/0067781-5, Relator: Ministro MARCO AURÉLIO BELLIZZE, Data de julgamento: 03/03/2015, T3 - TERCEIRA TURMA, Data de Publicação: DJe 10/03/2015. Disponível em: < https://stj.jusbrasil.com.br/jurisprudencia/178417344/recursoespecial-resp-1454643-rj-2014-0067781-5/relatorio-e-voto-178417366? ref=juris-tabs >. Acessado em 30 de jul. 2018.

TJ-MG - AC: 10024110578655001 MG, Relator: MOREIRA DINIZ, Data de julgamento 05/09/2013, Câmaras Cíveis/4a CÂMARA CíVEL, Data de Publicação: 12/09/2013. Disponível em: < https://tjmg.jusbrasil.com.br/jurisprudencia/116979426/apelacao-civel-ac-10024110578655001mg?ref=serp >. Acessado em 30 de jul. 2018.

TJ-SE - AC: 2010215409 SE, Relator: DES. OSÓRIO DE ARAUJO RAMOS FILHO, Data de julgamento: 17/12/2010, 2a. CÂMARA CÍVEL. Disponível em: < https://tjse.jusbrasil.com.br/jurisprudencia/18125192/apelacao-civel-ac-2010215409-se-tjse?ref=serp >. Acessado em 30 de jul. 2018. 